\title{
EFFECT OF PHYTOESTROGENS ON LIPID PROFILE: MINI REVIEW
}

\author{
NAGAMMA T, AKSHAY T JAGADEESH, ANJANEYULU K, KUMAR MR BHAT*
}

Department of Anatomy, Ras Al Khaimah College of Medical Sciences, RAK Medical \& Health Sciences University, UAE. Email: kumarbhat@rakmhsu.ac.ae

Received: 15 October 2016, Revised and Accepted: 28 October 2016

ABSTRACT

Phytoestrogens are structurally similar to its mammalian counterparts and are capable of producing estrogen-like effects and non-steroidal in nature. Their affinity to bind to the estrogen receptors, a class of cytoplasmic proteins, is far less in comparison to the natural estrogen hormones found in humans and other animals or even the synthetically prepared estrogen and, therefore, are far less potent. Even so, the usage of phytoestrogen in either dietary or supplemental form in postmenopausal women is gaining interest, as opposed to the conventional estrogen replacement therapy (ERT), which was so far being used to alleviate the postmenopausal symptoms and believed, with little experimental/clinical evidence, to cause a significant reduction in the threat of coronary heart diseases (CHD). This usage of phytoestrogen follows from the fact that the overall health risks exerted by ERT outweigh the benefits, and to a little extent, the perception that synthetically prepared, so-called "prescription estrogen" interferes with what is otherwise a natural process. It is crucial to explore the alternatives that mimic the beneficial effects of ERT, especially with regard to the minimization of the risk of developing CHD and further evaluation of the aforementioned risks in terms of lipid profiling while simultaneously keeping the health risks to a minimum. This review discusses the scope of use of phytoestrogen specifically pertaining to lipid profiling, their possible health benefits, and adverse effects if any.

Keywords: Phytoestrogens, Postmenopause, Lipid profile, Isoflavones.

(C) 2017 The Authors. Published by Innovare Academic Sciences Pvt Ltd. This is an open access article under the CC BY license (http://creativecommons. org/licenses/by/4. 0/) DOI: http://dx.doi.org/10.22159/ajpcr.2017.v10i2.15684

\section{INTRODUCTION}

\section{Estrogen and lipid profile in woman}

Menopause is a natural biological phenomenon associated with depletion of estradiol production. The decreased estrogen with menopause can impact coronary heart disease (CHD) risk factors by altering lipoprotein levels [1]. Women in younger age group have a lesser risk for cardiovascular events compared with men of their age. Reasons for protection from cardiovascular disease in younger women are complex; however, a significant contribution of estrogen attributed to the greater levels of high-density lipoprotein (HDL) in younger women. Moreover, low-density lipoprotein (LDL) and total cholesterol levels are low in premenopausal women than same age-matched men [2]. This becomes vitally important for women in menopausal transition when preventive measures can significantly improve both the quality and the quantity of their life. After natural or surgical menopause, the total cholesterol and LDL cholesterol (LDL-c) rise [3], HDL cholesterol (HDL-c) decreases slightly or may not change [4]. This may be due to the loss of estrogen's protection. Consequently, a number of clinical trials have reported that estrogen has a positive effect on lipid levels, endothelial cell function, vascular reactivity, and hemostatic factors in postmenopausal women. Serum lipid levels are low in women up to the age of 50 years as compared with men; however, after menopause, serum cholesterol level in women exceeds that of men [5]. Elevated cholesterol level accompanied by loss of endogenous estrogen secretion increases the risk of developing coronary artery disease in postmenopausal women [6]. Population-based studies revealed the beneficial effect of hormone replacement therapy in postmenopausal women contrary to the cardiovascular disorders [7-9]. The postmenopausal estrogen/ progestin interventions trial revealed that ERT in postmenopausal women convincingly showed significant decline in levels of lipoprotein (a), LDL, and increased levels of HDL [10].

However, the recent clinical trials such as the heart and estrogen/ progestin replacement study have brought us some unpredicted or even surprising findings $[11,12]$. For example, ERT did not elicit significant beneficial effects on cardiac function in women with CHD, thus making the clinical application of ERT improve the overall cardiovascular health somewhat controversial $[11,12]$. However, the long-term use of estrogen therapy has been found to increase the risk of endometrial and breast cancer [13-16]. Hence, the search for efficacious alternative strategies is in high demand to resolve the estrogen deficiency-related cardiovascular complications in postmenopausal women. Recently, attention has been drawn to the value of plant-derived phytoestrogen as a potential replacement for estrogen.

\section{PHYTOESTROGENS}

Phytoestrogens are polyphenolic non-steroidal naturally occurring photochemical substances that are found in foods of plant origin and possess a wide range of biochemical benefits which have been found to contribute favorably to different health-related problems. They may lower LDL-c without inducing hypertriglyceridemia $[17,18]$ and also decreases postmenopausal osteoporosis [19], protective effect against breast cancer [20], and neuroprotective [21]. These seem to possess both estrogenic and anti-estrogenic effects due to their similarity in structure to estrogen, the overall effect produced depending on the amount of circulating endogenous estrogen, the type of the tissue that it binds to, as well as the receptor regulation and perhaps to a little extent on the source and class to which the phytoestrogen belongs.

Phytoestrogens consist of more than 20 compounds and could be found in over 300 plants [22,23]. There are main three classes of phytoestrogens, which include isoflavones, lignans, and coumestans. Other phytoestrogens comprise stilbenes, flavonols, flavanones, and flavones. Isoflavones are natural non-steroidal molecules with structural similarity to $17-\beta$ estradiol and selective estrogen receptor modulators. Genistein and daidzein are two of the thousands of isoflavones that are most extensively investigated as they are thought to possess extremely high estrogenic activity. Legumes such as soy, clover, chickpeas, beans, and lentils are the rich sources of isoflavones [24]. The lignans were commonly present in the plant kingdom, and the lignin was found in 
the plant cell wall. This is found huge quantities in flaxseed and to a little extent in whole grains, beans, lentils, fruits, and vegetables. They are thought to possess antitumorigenic and antioxidant properties as well [25]. Coumestans are found in mung bean sprouts, spinach, sprouts, and brussel. The most important coumestan consumed by humans is in the form of coumestrol. Resveratrol and pterostilbene, belonging to the family of stilbenes, are commonly found in peanuts and red wine. Estrogenic activity is exhibited by resveratrol only in the Trans form [26].

\section{ISOFLAVONES}

Chemical nature: Polyphenolic compounds with twelve different forms. Source: Richest in soybeans and soy products.

Biologically active form: Aglycone form.

\section{Animal studies}

Soy isolates containing isoflavonic phytoestrogens have favorable effects on lipid profiles, without any adverse effect on the reproductive system in prepubertal Rhesus monkeys [27]. The US Food and Drug Administration approved that " $25 \mathrm{~g}$ of soy protein a day, as part of a diet low in saturated fat and cholesterol, may reduce the risk of heart disease" (Food and Drug Administration, 1999). A randomized, doubleblind study carried out by investigators [28] on white male cholesterolfed rabbits to check the effects of probiotic bacteria, simvastatin, and isoflavones on lipid profile showed that animal groups on a hypercholesterolemic diet supplemented with soy isoflavones reduced the serum total cholesterol and non-HDL-c concentration albeit this reduction was not of much statistical importance in comparison to those animal groups that were fed on hypercholesterolemic diets plus simvastatin, a cholesterol-lowering drug or even those groups that were supplemented with a probiotic microorganism Enterococcus faecium CRL 183. Animal experiments have shown that the serum lipidlowering properties of soy protein are primarily due to the presence of isoflavones [29]. Soy contents of 7S globulin protein possibly upregulate LDL receptors and thereby reduce serum LDL concentrations has shown by some of the in vitro studies [30]. Zucker rats were fed with soy protein enriched with isoflavones for 42 days reduced fatty liver and reduced the plasma levels of aspartate transaminase and alanine transaminase, increased activities of acetyl-CoA carboxylase, mitochondrial and peroxisomal beta-oxidation, fatty acid synthase, and glycerol-3-phosphate acyltransferase in liver. These results are accompanied by decreased hepatic mRNA level of VLDL receptor and increased plasma triacylglycerol level [31].

\section{Human studies}

A meta-analysis of 29 articles established that the intake of soy protein in humans showed significant improvement in lipid profile [17]. The 29 articles included 38 clinical trials, of which 34 trials included adult subjects and 4 with children as subjects, all of which were analyzed independently. The analysis drew a consistent finding that replacement of animal protein with soy protein led to a significant reduction in LDL-c and serum cholesterol in 34 of the 38 trials; in the 4 trials, did not report such conspicuous reductions; the subjects had a properly normal main cholesterol values. It was also noted that the variations in the serum lipid profile concentrations were independent of changes in body weight, dietary intake of cholesterol, total fat, and saturated fat while the factor responsible for the variance observed among the studies was the initial serum cholesterol concentrations. Randomized, double-blind, placebocontrolled study to check the effects of soy protein in postmenopausal women on lipid profile with mild hypercholesterolemia showed a positive effect on lipid levels, i.e., a significant reduction in LDL and serum cholesterol levels but also showed that statistically similar values can be obtained with a placebo-milk protein [32].

A relatively recent meta-analytical study concerning the effects of isoflavonic soy protein on lipid profile of 11 randomized controlled trials published from 1990 to 2006 identified by PUBMED concluded that isoflavones present in soy protein significantly reduced serum total cholesterol, triacylglycerol, and LDL-c, and significantly improved
HDL cholesterol; however, the changes are associated with duration of intake, level, and sex [29]. Studies with intakes $>80 \mathrm{mg} /$ day showed more favorable effects on lipid profile in comparison to the ones with lower intakes. The HDL concentration increase was seen in only those subjects where the phytoestrogen intake was continued for over 12 weeks as opposed to the reductions in LDL, serum total cholesterol, and triacylglycerol concentrations which occurred first. As for the variations in sex, it was noted that the decline in serum cholesterol, LDL-c was seen to a much greater degrees in men than in women. The meta-analysis drew conclusions that the initial serum cholesterol level played a great role in the effects seen post phytoestrogen intake owing to a greater decrease in risk factors in hypercholesterolemic patients than in subjects with baseline cholesterol values [33].

The American Heart Association recognizes that eating soy protein can help decrease LDL-c levels by two to seven percent $[34,35]$. In an another study, it was reported that soy protein decreased LDL-c levels five to six percent [36]. Soy protein may have rendered beneficial effects on lipid profile; however, these data are insufficient to conclude that isoflavone component, i.e., phytoestrogens, is responsible for the results produced as alcohol-extracted soy protein isoflavones without soy protein do not affect serum lipid profile in hypercholesterolemic men, indicating that isoflavones interacting with other components of soy protein may be responsible for the results observed [37]. In 2006, Reynolds et al. by a meta-analysis found that significant reduction in triglycerides (TG), cholesterol, and LDL and increased HDL levels [38]. A recent study in type 2 diabetes mellitus people showed that daily dose of 60 grams soy nuts for two months caused a significant reduction in the levels of total cholesterol, LDL-c; however, it did not show a significant effect on the levels of TG and HDL-c [39].

A very real point of uncertainty is regarding the long-term effects that these substances can have on the body. A 2008 clinical report [40] showed that data regarding phytoestrogens are not sufficient enough to ascertain whether the incorporation of these substances in daily diets beyond a certain measure is medically safe. The report documented abnormal uterine bleeding with endometrial pathology in three women (aged 35-56), all of whom were accustomed to a relatively high intake of soy products in their diets. In all three women, it was found that after the reduction or elimination of soy product intake, their symptoms ameliorated leading to conclusions that long-term consumption of phytoestrogens could be harmful. Large intervention trials designated that soy protein intake will affect CHD risk immediately after the menopause [41]. Recently, few soy interventional studies [42,43] have found little or no beneficial effect on serum lipid levels.

\section{Lignans}

Chemical nature: Dimeric phenylpropanoids.

Source: Richest in flaxseed (linseed).

Whether the cholesterol-lowering activities of flaxseed is to be attributed to one of its components or an interaction between the varying components was an issue that needed to be dealt with, for flaxseed a rich source of dietary fiber which in itself is an established cholesterol-lowering agent [44], is also rich in $\alpha$-linolenic acid - an $\omega$-3 fatty acid - A substance thought to bring about a favorable lipid profile and also rich in lignans - substances seeming to possess estrogenic activities, with insufficient evidence regarding the latter two.

\section{Animal studies}

The component present in flaxseed is $\alpha$-linolenic acid which is responsible for the hypocholesterolemic activity. Type II flaxseed (CDC-flaxseed) which has similar lignan and oil content but has very little $\alpha$-linolenic acid would have no such effects. A study carried out to check the action of CDC-flaxseed/Type II flaxseed on lipid profiles in rabbits concluded that the cholesterol-lowering properties of flaxseed were independent of the $\alpha$-linolenic acid component [45]. This could be extrapolated to believe that the antiatherogenic properties of flaxseed could be attributed to their lignan components though further studies are required to unequivocally establish this. A study carried out with 
flax seed chutney was able to lower the cholesterol levels and shown the antioxidant protective effect against the carbon tetrachlorideinduced hepatotoxic damage in rats [46]. To check the effects of linseed consumption on lipid profile in rabbits on a hypercholesterolemic diet, investigators conducted an experimental study involving a total of 20 adult male white rabbits that were divided into two groups, a control and an experimental group. Both groups were fed on a specific diet plus $1 \%$ cholesterol from a lyophilized egg throughout the 56-day course of the study. In addition, the experimental group was fed ground linseed $(8 \mathrm{~g} / \mathrm{kg})$ from day 29 to 56 . The study drew conclusions that although there was an elevated level of serum total cholesterol in both groups, this increase was highly significant with the control group. Also noted was that LDL-c was lower in the group that was supplemented with linseed whereas the HDL-c and serum TG showed insignificant differences between the two groups [47].

\section{Human studies}

A randomized controlled, double-blind parallel study conducted to check the efficacy of flaxseed (Type I flaxseed) on lipid profile concluded that the supplementation of the diet of postmenopausal women with ground whole flaxseed of $40 \mathrm{~g}$, consumed daily for a period of 3-month, resulted in decrease of serum levels of both low-density and HDL-c by $4.7 \%$ and triglyceride concentration by $12.8 \%$, though these changes were statistically insignificant, it was rather in contrast to the group that was supplemented with a wheat-based comparative regimen [48]. The effectiveness of flaxseed and its derivatives on serum lipid profiles in adult investigators [49] carried out a metaanalysis of 28 randomized controlled trials which showed that whole flaxseed interventions resulted in significant decrease in LDL and total cholesterol, in contrast to flaxseed oil that exerted only a statistically insignificant effect perhaps because flaxseed oil lacks dietary fiber and lignans. Flaxseed and its products were shown favorable effects on those with relatively high primary cholesterol concentrations leading to believe that the primary cholesterol levels played a very influential role in their action. Also noted was that the hypocholesterolemic effect was more pronounced in women than in men, the reasons for which remain uncertain and need further evaluation.

\section{Coumestans}

Chemical nature: Coumestrol.

Source: Legumes are the main source of coumestrol.

Very few studies have been reported in this area. It was observed that ovariectomized rats receive the coumestrol showed the anabolic effect on cholesterol in liver [50]. Nogowski et al. reported coumestrol had no significant effect on plasma insulin or glucagon concentrations [51]. In another study, dietary coumestrol in chicks decreased plasma cholesterol concentrations in a dose-dependent manner [52].

Another phytoestrogen-containing dietary hypolipidemic herbal product is seeds of fenugreek. Fenugreek seeds are an important component of Indian spices that are used regularly in Indian foods. Trigonella foenum graecum commonly known as fenugreek belongs to the family Fabaceae. The plant contains active constituents such as alkaloids, flavonoids, steroids, and saponins [53]. Diosgenin, which is used to make synthetic estrogen, is present in Fenugreek seeds. In 2014, Kumar et al. stated the hypolipidemic effect of Fenugreek seed extract on high--fat diet-induced obese rats [54]. Abedinzade et al. in 2015 reported the antihyperlipidemic effect of fenugreek seed extract in ovariectomized rats [55]. The steroidal components (saponins and sapogenin) present in fenugreek seeds are responsible for hypolipidemic effect [56]. Other mechanisms responsible for hypolipidemic effect include activation of lecithin-cholesterol acyl transferase, lipoprotein lipase, triglyceride lipase, and increased excretion of bile acids. Thermostable extract of fenugreek seeds can inhibit the fat accumulation in differentiated cells through reduced adipogenic factors expression such as peroxisome proliferators activated receptor- $\gamma$, CAAT element binding proteins- $\alpha$ and sterol regulatory element-binding protein- $1[57,58]$. In a study, a dose of
$1000 \mathrm{mg} /$ day supplementation of a standardized extract of fenugreek to postmenopausal women, showed a significant increase in plasma estradiol level and improvement in the quality of life of the postmenopausal woman. Biochemical parameters showed positive role in the management of lipid profile values [59]

Our pilot data (unpublished) also showed the beneficial effect of fenugreek seed extract in ovariectomized rats. After the treatment with fenugreek, ovariectomized rats showed decreased cholesterol level. These rats also showed better memory and learning after the treatment with fenugreek. Presently we are evaluating the role of fenugreek seed extract on various inflammatory markers, certain genes that are associated with energy storage, lipid metabolism and adipocyte differentiation using ovariectomized rat as a menopausal model.

\section{CONCLUSION}

The majority of the studies suggest increased phytoestrogen intake especially in those subjects with pre-existing hypercholesterolemia result in lower serum total cholesterol and LDL levels, and in some cases lead to an increase in HDL levels the latter result being achieved only on prolonged consumption. The extent of these changes is in proportion to intake both quantity and duration, the source and thereby the specific type of phytoestrogen consumed. The factor that acts as a modulator of these effects produced seems to be the initial blood lipid values. Though these results reach statistical significance in most studies considered in this review, whether dietary supplementation of phytoestrogens can replace the well-established cholesterol lowering agents, statins, is probably something that cannot be answered at the moment. Further, the small sample sizes, variability in the study designs, various types of phytoestrogens used, different doses and duration of treatment preventing us from drawing any firm conclusion.

\section{REFERENCES}

1. Woodard GA, Brooks MM, Barinas-Mitchell E, Mackey RH, Matthews KA, Sutton-Tyrrell K. Lipids, menopause, and early atherosclerosis in Study of Women's Health Across the Nation Heart women. Menopause 2011;18(4):376-84.

2. Jensen J, Nilas L, Christiansen C. Influence of menopause on serum lipids and lipoproteins. Maturitas 1990;12(4):321-31.

3. Yazdani S, Sharbatdaran M, Abedi Samakoosh M, Bouzari Z, Masoudi Z. Glucose tolerance and lipid profile changes after surgical menopause. Caspian J Intern Med 2014;5(2):114-7.

4. Tuna V, Alkis I, Safiye AS, Imamoglu N, Bayram N, Ali Ismet T. Variations in blood lipid profile, thrombotic system, arterial elasticity and psychosexual parameters in the cases of surgical and natural menopause. Aust N Z J Obstet Gynaecol 2010;50(2):194-9.

5. Bingham SA, Atkinson C, Liggins J, Bluck L, Coward A. Phytooestrogens: Where are we now? Br J Nutr 1998;79:393-406.

6. Dewell A, Hollenbeck CB, Bruce B. The effects of soy-derived phytoestrogens on serum lipids and lipoproteins in moderately hypercholesterolemic postmenopausal women. J Clin Endocrinol Metab 2002;87:118-21.

7. Grodstein F, Stampfer MJ, Manson JE, Colditz GA, Willett WC, Rosner B, et al. Postmenopausal estrogen and progestin use and the risk of cardiovascular disease. N Engl J Med 1996;335(7):453-61.

8. Barrett-Connor E, Bush TL. Estrogen and coronary heart disease in women. JAMA 1991;265(14):1861-7.

9. Stampfer MJ, Colditz GA. Estrogen replacement therapy and coronary heart disease: A quantitative assessment of the epidemiologic evidence. Prev Med 1991;20(1):47-63.

10. Mosca L, Grundy SM, Judelson D, King K, Limacher M, Oparil S, et al. Guide to preventive cardiology for women. AHA/ACC scientific statement consensus panel statement. Circulation 1999;99(18):2480-4.

11. Subbiah MT. Estrogen replacement therapy and cardioprotection: Mechanisms and controversies. Braz J Med Biol Res 2002;35(3):271-6.

12. Mosca L, Collins P, Herrington DM, Mendelsohn ME, Pasternak RC, Robertson RM, et al. Hormone replacement therapy and cardiovascular disease: A statement for healthcare professionals from the American Heart Association. Circulation 2001;104(4):499-503.

13. Beral V, Reeves G, Bull D, Green J; Million Women Study Collaborators. Breast cancer risk in relation to the interval between menopause and starting hormone therapy. J Natl Cancer Inst 2011;103(4):296-305. 
14. Chlebowski RT, Anderson G, Manson JE, Pettinger M, Yasmeen S, Lane D, et al. Estrogen alone in postmenopausal women and breast cancer detection by means of mammography and breast biopsy. J Clin Oncol 2010;28(16):2690-7.

15. Brinton LA, Felix AS. Menopausal hormone therapy and risk of endometrial cancer. J Steroid Biochem Mol Biol 2014;142:83-9.

16. Weiderpass E, Baron JA, Adami HO, Magnusson C, Lindgren A, Bergström R, et al. Low-potency oestrogen and risk of endometrial cancer: A case-control study. Lancet 1999;353(9167):1824-8.

17. Anderson JW, Johnstone BM, Cook-Newell ME. Meta-analysis of the effects of soy protein intake on serum lipids. N Engl J Med 1995;333(5):276-82.

18. Hooper L, Kroon PA, Rimm EB, Cohn JS, Harvey I, Le Cornu KA, et al. Flavonoids, flavonoid-rich foods, and cardiovascular risk: A meta-analysis of randomized controlled trials. Am J Clin Nutr 2008;88(1):38-50

19. Rojas J, Londono C, Ciro Y. The health benefits of natural skin UVA photoprotective compounds found in botanical sources. Int J Pharm Pharm Sci 2016;8(3):13-23.

20. Andres S, Abraham K, Appel KE, Lampen A. Risks and benefits of dietary isoflavones for cancer. Crit Rev Toxicol 2011;41(6):463-506.

21. Zhao L, Mao Z, Brinton RD. A select combination of clinically relevant phytoestrogens enhances estrogen receptor beta-binding selectivity and neuroprotective activities in vitro and in vivo. Endocrinology 2009;150(2):770-83

22. Murkies AL, Wilcox G, Davis SR. Clinical review 92: Phytoestrogens. J Clin Endocrinol Metab 1998;83:297-303.

23. Thame DM, Gardener CD, Haskell WL. Potential health benefits of dietary phytoestrogens: A review of clinical, epidemiological and mechanistic evidence. J Clin Endocrinol Metab 1998;83(7):2223.

24. Thompson LU, Boucher BA, Liu Z, Cotterchio M, Kreiger N. Phytoestrogen content of foods consumed in Canada, including isoflavones, lignans, and coumestan. Nutr Cancer 2006;54(2):184-201.

25. Gupta D, Kaur P. Phytochemical evaluation and in vitro antioxidant activity of few wonder seeds. Int J Pharm Pharm Sci 2016;8(7):98-104.

26. Schmitt E, Lehmann L, Metzler M, Stopper H. Hormonal and genotoxic activity of resveratrol. Toxicol Lett 2002;136(2):133-42.

27. Anthony MS, Clarkson TB, Hughes CL Jr, Morgan TM, Burke GL. Soybean isoflavones improve cardiovascular risk factors without affecting the reproductive system of peripubertal rhesus monkeys. J Nutr 1996;126(1):43-50.

28. Cavallini DC, Bedani R, Bomdespacho LQ, Vendramini RC, Rossi EA. Effects of probiotic bacteria, isoflavones and simvastatin on lipid profile and atherosclerosis in cholesterol-fed rabbits: A randomized double-blind study. Lipids Health Dis 2009;8:1

29. Zhan S, Ho SC. Meta-analysis of the effects of soy protein containing isoflavones on the lipid profile. Am J Clin Nutr 2005;81(2):397-408

30. Ferreira Ede S, Silva MA, Demonte A, Neves VA. Soy ß-conglycinin (7S globulin) reduces plasma and liver cholesterol in rats fed hypercholesterolemic diet. J Med Food 2011;14(1-2):94-100.

31. Gudbrandsen OA, Wergedahl H, Mørk S, Liaset B, Espe M, Berge RK. Dietary soya protein concentrate enriched with isoflavones reduced fatty liver, increased hepatic fatty acid oxidation and decreased the hepatic mRNA level of VLDL receptor in obese Zucker rats. Br J Nutr 2006;96:249-57.

32. Blum A, Lang N, Vigder F, Israeli P, Gumanovsky M, Lupovitz S, et al. Effects of soy protein on endothelium-dependent vasodilatation and lipid profile in postmenopausal women with mild hypercholesterolemia. Clin Invest Med 2003;26:20-6.

33. Taku K, Umegaki K, Sato Y, Taki Y, Endoh K, Watanabe S. Soy isoflavones lower serum total and LDL cholesterol in humans: A meta-analysis of 11 randomized controlled trials. Am J Clin Nutr 2007;85:1148-56.

34. Sacks FM, Lichtenstein A, Van Horn L, Harris W, Kris-Etherton P, Winston M; American Heart Association Nutrition Committee. Soy protein, isoflavones, and cardiovascular health: An American Heart Association Science Advisory for professionals from the Nutrition Committee. Circulation 2006;113:1034-44.

35. Høie LH, Graubaum HJ, Harde A, Gruenwald J, Wernecke KD. Lipid-lowering effect of 2 dosages of a soy protein supplement in hypercholesterolemia. Adv Ther 2005;22:175-86.

36. Anderson JW. Soyfoods effects on serum lipoproteins in humans: Updated meta-analysis. Oral Presentation at $6^{\text {th }}$ International Symposium on the Role of Soy in Preventing and Treating Chronic Disease. Chicago; 2005

37. Amani R. We-P14:413 effects of soy protein isoflavones on serum lipid profile and hormones of hypercholesterolemic men. Atheroscler 2006;7:438

38. Reynolds K, Chin A, Lees KA, Nguyen A, Bujnowski D, He J. A metaanalysis of the effect of soy protein supplementation on serum lipids. Am J Cardiol 2006;98:633-40.

39. Sedaghat A, Shahbazian H, Haidari F, Payami S, Jahanshahi A, Latifi, S. The effect of soy nuts on glycemic control, lipid profile and insulinresistance in Type 2 diabetic patients. Endocr Metab Dis 2015;5:1-7.

40. Chandrareddy A, Muneyyirci-Delale O, McFarlane SI, Murad OM. Adverse effects of phytoestrogens on reproductive health: A report of three cases. Complement Ther Clin Pract 2008;14(2):132-5.

41. Hodis HN, Mack WJ, Kono N, Azen SP, Shoupe D, Hwang-Levine J, et al. Isoflavone soy protein supplementation and atherosclerosis progression in healthy postmenopausal women: A randomized controlled trial. Stroke 2011;42(11):3168-75

42. Campbell SC, Khalil DA, Payton ME, Arjmandi BH. One-year soy protein supplementation does not improve lipid profile in postmenopausal women. Menopause 2010;17(3):587-93.

43. Wofford MR, Rebholz CM, Reynolds K, Chen J, Chen CS, Myers L, et al. Effect of soy and milk protein supplementation on serum lipid levels: A randomized controlled trial. Eur J Clin Nutr 2012;66(4):419-25.

44. Brown L, Rosner B, Willett WW, Sacks FM. Cholesterol-lowering effects of dietary fiber: A meta-analysis. Am J Clin Nutr 1999;69:30-42.

45. Prasad K, Mantha SV, Muir AD, Westcott ND. Reduction of hypercholesterolemic atherosclerosis by CDC-flaxseed with very low alpha-linolenic acid. Atherosclerosis 1998;136(2):367-75.

46. Shakir KA, Madhusudhan B. Hypocholesterolemic and hepatoprotective effects of flaxseed chutney: Evidence from animal studies. Indian J Clin Biochem 2007;22(1):117-21.

47. Prim CR, Baroncini LA, Précoma LB, Caron PH, Winter G, Poletti MO, et al. Effects of linseed consumption for a short period of time on lipid profile and atherosclerotic lesions in rabbits fed a hypercholesterolaemic diet. Br J Nutr 2012;107(5):660-4.

48. Lucas EA, Wild RD, Hammond LJ, Khalil DA, Juma S, Daggy BP, et al. Flaxseed improves lipid profile without altering biomarkers of bone metabolism in postmenopausal women. J Clin Endocrinol Metab 2002;87(4):1527-32

49. Pan A, Yu D, Demark-Wahnefried W, Franco OH, Lin X. Meta-analysis of the effects of flaxseed interventions on blood lipids. Am J Clin Nutr 2009;90:288-97.

50. Nogowski L. Effects of phytoestrogen-coumestrol on lipid and carbohydrate metabolism in young ovariectomized rats may be independent of its estrogenicity. J Nutr Biochem 1999;10(11):664-9.

51. Nogowski L, Nowak KW, Mackowiak P. Effect of phytooestrogen coumestrol and oestrone on some aspects of carbohydrate metabolism in ovariectomized female rats. Arch Vet Pol 1992;32(3-4):79-84.

52. Béguin DP, Kincaid RL. 3-Hydroxy-3-methyl-glutaryl coenzyme A reductase activity in chicks fed coumestrol, a phytoestrogen. Poult Sci 1984:63:686-90.

53. Ahirwar D, Ahirwar B. Evaluation of antifertility activity of Trigonella foenum graecum seeds. Der Pharm Sin 2010;1(3):33-9.

54. Kumar P, Bhandari U, Jamadagni S. Fenugreek seed extract inhibit fat accumulation and ameliorates dyslipidemia in high fat diet-induced obese rats. Biomed Res Int 2014;606021.

55. Abedinzade M, Nasri S, Omidi MJ, Porramezan B, Khanaki K. The effect of fenugreek (Trigonella foenum-graecum) seed and 17- $\beta$ estradiol on serum apelin, glucose, lipids and insulin in ovariectomized rats. Biotechnol Health Sci 2015;2(3): 30402.

56. Sharma RD, Raghuram TC, Rao NS. Effect of fenugreek seeds on blood glucose and serum lipids in type I diabetes. Eur J Clin Nutr 1990;44(4):301-6.

57. Vijayakumar MV, Pandey V, Mishra GC, Bhat MK. Hypolipidemic effect of fenugreek seeds is mediated through inhibition of fat accumulation and upregulation of LDL receptor. Obesity (Silver Spring) 2010;18(4):667-74

58. Chaturvedi U, Shrivastava A, Bhadauria S, Saxena JK, Bhatia G. A mechanism-based pharmacological evaluation of efficacy of Trigonella foenum graecum (fenugreek) seeds in regulation of dyslipidemia and oxidative stress in hyperlipidemic rats. J Cardiovasc Pharmacol 2013;61(6):505-12.

59. Shamshad Begum S, Jayalakshmi HK, Vidyavathi HG, Gopakumar G, Abin I, Balu M, et al. A novel extract of fenugreek Husk (FenuSMART ${ }^{\mathrm{TM}}$ ) alleviates postmenopausal symptoms and helps to establish the hormonal balance: A randomized, double-blind, placebocontrolled study. Phytother Res 2016;30:1775-84 